\title{
High Time-Resolution Optical Sensor for Monitoring Atmospheric Nitrogen Dioxide
}

\author{
Yong Tian, ${ }^{\dagger}$ Xiaomin Zhang, ${ }^{\ddagger}$ Huiyan Shen, ${ }^{\ddagger}$ Aifeng Liu, ${ }^{\dagger}$ Zongshan Zhao, ${ }^{*}{ }^{\dagger}$ Ming-Li Chen, ${ }^{\ddagger}$ \\ and $\mathrm{Xu}-\mathrm{Wei}$ Chen ${ }^{*},+0$ \\ ${ }^{\dagger}$ CAS Key Laboratory of Biobased Materials, Qingdao Institute of Bioenergy and Bioprocess Technology, Chinese Academy of \\ Sciences, Qingdao 266101, China \\ ${ }^{\ddagger}$ Research Center for Analytical Sciences and Department of Chemistry, College of Sciences, Northeastern University, Shenyang \\ 110819, China
}

Supporting Information

ABSTRACT: High time-resolution monitoring of nitrogen dioxide $\left(\mathrm{NO}_{2}\right)$ is of great importance for studying the formation mechanism of aerosols and improving air quality. Based on the Griess-Saltzman (GS) reaction, a portable $\mathrm{NO}_{2}$ optical sensor was developed by employing a porous polypropylene membrane tube (PPMT) integrated gas permeation collector and detector. The PPMT was filled with GS reagents and covered with a coaxial jacket tube for gas collection. Its two ends were respectively fixed with a yellowish-green light-emitting diode and a photodiode for optic signal reception. $\mathrm{NO}_{2}$ was automatically introduced through the collector by two air pumps cooperating with a homemade gas injector. Under the optimized conditions, the device presented good performance for monitoring $\mathrm{NO}_{2}$, such as a limit of detection of 5.1 ppbv (parts per billion by volume), an intraday precision of $4.1 \%$ (RSD, relative standard deviation, $n=11, c=100 \mathrm{ppbv}$ ), an interday precision of $5.7 \%$ (RSD, $n=2-3$ per day for 5 days, $c=100 \mathrm{ppbv}$ ), an analysis time of $4.0 \mathrm{~min}$, and a linearity range extended to $700 \mathrm{ppbv}$. The developed device was successfully applied to analyzing outdoor air with a comparable precision to that of the standard method of China. The high timeresolution characteristic that includes sampling 15 times per hour and a good stability for 10 days of urban air analysis had also been evaluated.
$\mathrm{N}^{\mathrm{s}}$ itrogen dioxide $\left(\mathrm{NO}_{2}\right)$ is well-known as a "criteria air pollutant" because of its role in aerosol formation, such as being a precursor of ozone and a major reactant of photochemical smog and particulate matter. ${ }^{1,2}$ With the improvement of the quality of life and transit mobility, a growing amount of $\mathrm{NO}_{2}$ from fossil fuel combustion has unintentionally been produced and emitted into the atmosphere. $^{3-5}$ Its arbitrary emissions have caused serious air pollution and induced various respiratory illnesses. ${ }^{6-9}$ In order to reduce its environmental effects (e.g., acid rain, air haze, and nutrient pollution) and to prevent acute and chronic harm to public health, $1 \mathrm{~h}$ daily maximum concentrations of atmospheric $\mathrm{NO}_{2}$ have been strictly regulated in China, ${ }^{10}$ the European Union, ${ }^{11}$ the United States, ${ }^{2}$ and other countries. ${ }^{12}$

For monitoring $\mathrm{NO}_{2}$ levels, many analytical techniques have been developed, including chemiluminescent assays, ${ }^{13,14}$ fluorescent methods, ${ }^{15-17}$ semiconductor gas sensors, ${ }^{18,19}$ electrochemical sensors, ${ }^{19-22}$ chromatographic methods, ${ }^{23-25}$ and integrated absorption spectroscopy devices. ${ }^{26,27}$ To date, a series of fluorescent probes and chromogenic reagents have been studied for gas sensing, ${ }^{28-32}$ but only the GriessSaltzman (GS) method has been proposed as the standard method for $\mathrm{NO}_{2}$ detection in China (HJ 479-2009). ${ }^{33}$ Although the accuracy of GS method has been validated for dozens of years, it still suffers from its complicated procedure, time-consuming coloration, unintegrated devices, and its requirement of a large sample volume of air.

Recently, portable optical devices assembled with lightemitting diodes and photodiodes present comparable sensitivity, selectivity, and stability as commercial spectrometers for component analysis. ${ }^{34-37}$ Based on the reactions between $\mathrm{NO}_{2}$ and 8-amino-1-naphthol-5-sulfonic acid $^{34}$ as well as calix[4]arenes, ${ }^{38}$ the Dasgupta group invented two optical transmission sensors for monitoring $\mathrm{NO}_{2}$. Besides high time-resolution performance (one sample per $5 \mathrm{~min}$ ), their limits of detection (LOD) were $0.64 \mathrm{ppbv}$ and $0.54 \mathrm{ppmv}$, respectively. In addition, the porous membrane tube has also been introduced into portable optical devices for gas collection. ${ }^{39}$ For these devices, either the impregnated plates with chromogenic agents are needed to be freshly prepared before measurements, or the amounts and flowing rate of the gas sample are hard to control.

In this paper, we develop a portable $\mathrm{NO}_{2}$ optical sensor by employing a porous polypropylene membrane tube (PPMT) integrated gas permeation collection and detection. An air

Received: September 1, 2017

Accepted: November 14, 2017

Published: November 14, 2017 
sample injector is employed for controlling gas amounts and flowing rate. The operating conditions for monitoring atmospheric $\mathrm{NO}_{2}$ have been systemically studied. And the performance of the developed device has been evaluated by comparison with the standard method of China.

\section{EXPERIMENTAL SECTION}

Device Construction. The sketch of the developed device is shown in Figures 1 and S1. The system shown in Figure S1 is

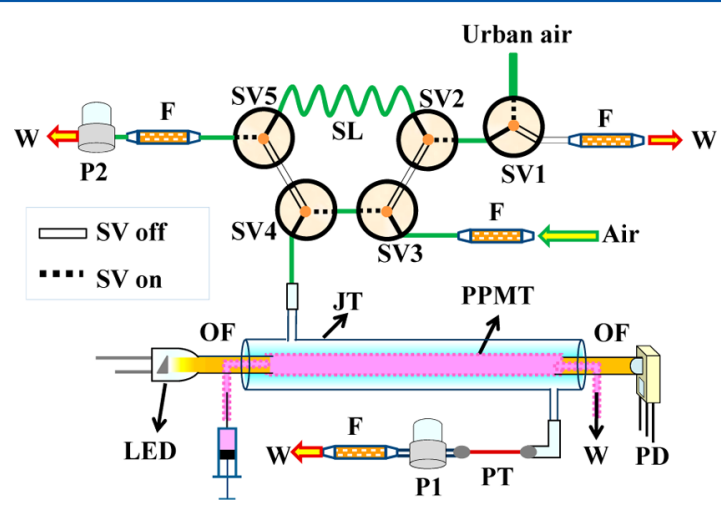

Figure 1. Schematic representation of the $\mathrm{NO}_{2}$ detection device for urban air analysis. SV: solenoid valve; F: sodium hydroxide filter; SL: sample loop; OF: optical fiber; LED: light-emitting diode; JT: jacket tube; PPMT: porous polypropylene membrane tube; PD: photodiode; PT: peek tube; P1 and P2: air pump; W: waste.

only used for standard $\mathrm{NO}_{2}$ detection. The standard $\mathrm{NO}_{2}$ was prepared by two mass flow controllers (MFC, 10 SLPM and 100SCCM, Shenzhen Flow Method Measure and Control System Co., Ltd., China, www.flowmethod.net), with $\mathrm{N}_{2}$ as dilution gas. All of the MFCs were calculated by a soap film gas flowmeter (SCal Plus, Beijing Municipal Institute of Labor Protection). In the case of standard gases prepared offline (e.g., prepared in bags), the sketch of the used device is shown in Figure 1. The gas sample injection system was assembled by five solenoid valves (SV) and a piece of PTFE tube $(200 \mathrm{~mL}$, i.d. $=1.0 \mathrm{~cm}, L=128 \mathrm{~cm})$. Homemade filters padded with sodium hydroxide were connected to one end of SV1, SV5, and air pump (P1) for receiving waste. Another filter connected with one entrance of SV3 was used to clean the acid and water vapor before the gas entered into the system.

The $\mathrm{NO}_{2}$ detection cell was basically assembled by a porous polypropylene membrane tube (PPMT, Accurel PP, $1.8 \mathrm{~mm}$ i.d., $2.0 \mathrm{~mm}$ o.d., $50 \mathrm{~mm}$ in length) with an outer jacket tube (5.0 mm i.d., $7 \mathrm{~mm}$ o.d., $50 \mathrm{~mm}$ in length), plastic optical fibers (poly(methyl methacrylate), PMMA, $2.0 \mathrm{~mm}$ i.d.), a lightemitting diode (LED, $560 \mathrm{~nm}$ ), and a light to voltage converter (Photodiode, TSL257, www.ams.com). The ends of the PPMT were connected to the polished LED and the photodiode via plastic optical fibers. Both fibers close to PPMT are machined with an L-shaped aperture $(0.50 \mathrm{~mm}$ i.d. $)$. The $\mathrm{GS}$ reagents are injected into and discharged out of the PPMT via the L-shaped apertures with two pieces of PTFE capillary tubing (PTFE extruded tubing, $0.30 \mathrm{~mm}$ i.d., $0.9 \mathrm{~mm}$ o.d., www.zeusinc.com). A coaxial outer jacket tube was used for gas diffusion collection. The two ends of the jacket tube were connected with PTFE tubing ( $2 \mathrm{~mm}$ o.d., $1.6 \mathrm{~mm}$ i.d.) as gas passageways. All joints were fixed with clear hot glue, and the whole detection cell was wrapped with black friction tape to eliminate interference from ambient light.
A micro air pump (P1, 310-B, $6 \mathrm{~V}$, www.fspump.cn) equipped with a length of PEEK tube (PT, $0.125 \mathrm{~mm}$ i.d.) was used to control the gas flow rate. A plastic syringe was used to inject and change the GS reagent in the PPMT. A 16-bit USB-based data acquisition (DAQ) board (USB-1608FS-Plus) and a laptop computer were employed for converting and recording the signal change of the photodiode. A DC regulated power supply (RPS3005D-2, www.chinarek.com) and lithiumion polymer battery (Yinuo, 12v, 80Ah) was used as the power supply in lab and in field analysis, respectively. The details of the electric circuit of LED, the light to voltage converter, DAQ and the solenoid valves are shown in Figure S2. ${ }^{40}$

Reagents, Sample Information, Experimental Procedure, and Data Analysis. The details of the reagents, sample information, experimental procedure, and data analysis are shown in the Supporting Information (Reagents and samples, Experimental procedures for standard $\mathrm{NO}_{2}$ detection, Experimental procedures for urban air analysis, and Data analysis).

\section{RESULTS AND DISCUSSION}

Spectrum Properties of the Light Sources and GS Reagent Solution. The Griess-Saltzman (GS) method has been approved and authorized for spectrometric determination of $\mathrm{NO}_{2}$ in air for decades. The reaction between $\mathrm{NO}_{2}$ and the GS reagent quantitatively produced a red-pink color azo dye that can be used for colorimetric determination of $\mathrm{NO}_{2}$. The schematic illustration for the GS reaction is shown in Figure S3. The absorption spectrum of the GS reagent solution, the absorption spectrum of GS reagent solution with absorbed $\mathrm{NO}_{2}$, and the LED emission spectrum are shown in Figure 2.

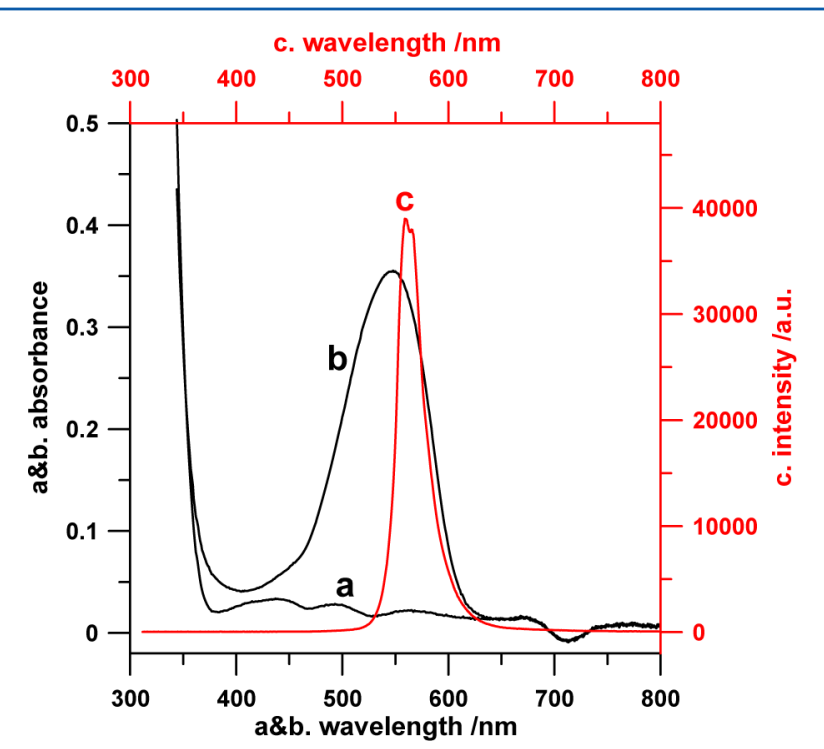

Figure 2. Spectroscopic details relevant to the measurement system. (a) Absorption spectrum of GS solution; (b) absorption spectrum of GS solution with absorbed $\mathrm{NO}_{2}$ (1000 ppbv, $2 \mathrm{~L}$ of $\mathrm{NO}_{2}$ absorbed in $10 \mathrm{~mL}$ of GS solution); and (c) LED emission spectrum.

As reported, the maximum absorption wavelength of the GS reagent solution with absorbed $\mathrm{NO}_{2}$ is about $540 \mathrm{~nm}$ (Figure $2 \mathrm{~b})$, and its spectrum domain is around 400 to $640 \mathrm{~nm}$. The emission wavelength of the yellowish-green LED is located between 520 to $640 \mathrm{~nm}$, which is narrower than that of the GS solution absorbed $\mathrm{NO}_{2}$ gas. As a result, this yellowish-green LED with maximum wavelength of $560 \mathrm{~nm}$ can be directly 
employed as the light source for the $\mathrm{NO}_{2}$ detection without any raster or optical prisms.

Effect of the Concentration of GS Solution for Monitoring $\mathrm{NO}_{2}$. According to the standard method $(\mathrm{HJ}$ 479-2009), the GS solution is composed of $4.0 \mathrm{~g} \mathrm{~L}^{-1}$ of sulfanilic acid, $40 \mathrm{~mL} \mathrm{~L}^{-1}$ of acetic acid, and $0.040 \mathrm{~g} \mathrm{~L}^{-1}$ of $n$-(1naphthyl)-ethylenediamine dihydrochloride. For obtaining good signals, reagent concentrations ranging from an 8-fold dilution to 2 times the concentration of the standard GS solution have been investigated (Figure S4a). It is obvious that the high concentration of the chromogenic reagent is beneficial for monitoring $\mathrm{NO}_{2}$. However, it is difficult to prepare high levels of sulfanilic acid due to its limited solubility in water. In order to avoid the PPMT being blocked by the crystallization of sulfanilic acid, the regular concentration of GS solution is used in the following study.

Effect of the Air Flow Rate for Monitoring $\mathrm{NO}_{2}$. Generally, the traditional GS reaction for detecting $\mathrm{NO}_{2}$ could be completed in about $15 \mathrm{~min}$. In this device, the GS reaction initially occurs on the gas-liquid interface. Its reaction process is closely related to the gas diffusion rate and reaction time, which are obviously affected by the gas flow rates.

In order to acquire the steady flow rate, a piece of red peek tube (PT in Figure 1, i.d. $125 \mu$ m, o.d. $1.6 \mathrm{~mm}$ ) is fixed between the air pump and the detection cell for controlling the gas flow rate. It has been found that the length of the tube can dramatically affect the signals (Figure S4b). Without the peek tube, the gas flow rate is about $1.0 \mathrm{~L} \mathrm{~min}^{-1}$, and it only takes ca. $12 \mathrm{~s}$ to finish the adsorption process, i.e., $200 \mathrm{~mL}$ of air sample completely passing through the detection cell. However, the high flow rate leads to incomplete absorption and color reaction. With the PT length increased from 0 to $2 \mathrm{~cm}$ (i.e., decreasing the air sample flow rate), the normalized signals rise simultaneously. Further increases of the PT length leads to no obvious, observable change of the signals. For further studies, a piece of PEEK tubing of $2.0 \mathrm{~cm}$ was adopted as the junction to control the air flow rate. In this case, the air flow rate is at about $50 \mathrm{~mL} \mathrm{m^{-1 }}$ as measured by the soap film flow meter.

Performance of the Device for Monitoring $\mathrm{NO}_{2}$. Under the optimized conditions, the standard $\mathrm{NO}_{2}$ gas (25 to 1000 ppbv) has been successfully detected by the assembled device. The linearity range extends to $700 \mathrm{ppbv}$ with the coefficient of determination $\left(R^{2}\right)$ of 0.9925 (Figure $\left.S 5\right)$. When the concentrations of $\mathrm{NO}_{2}$ are above the stated range $(>1000$ ppbv), a quadratic calibration equation can be used for its calibration. Since $\mathrm{NO}_{2}$ concentrations in urban air are generally below 1000 ppbv, high levels of $\mathrm{NO}_{2}$ have not been investigated in this study. The limit of detection (LOD, S/N = 3) for monitoring atmospheric $\mathrm{NO}_{2}$ is $5.1 \mathrm{ppbv}$, and the relative standard deviation (RSD) is $4.1 \%$ for 11 successive determinations of $100 \mathrm{ppbv}$ of $\mathrm{NO}_{2}$. Each run for monitoring $\mathrm{NO}_{2}$ can be finished in $4 \mathrm{~min}$, containing about $200 \mathrm{~s}$ for data acquisition and about $40 \mathrm{~s}$ for sample loading and GS reagent solution changing. This indicates that the time resolution of our device is of $15 \mathrm{~h}^{-1}$. The interday precision has also been evaluated, with an RSD of $5.7 \%(n=2-3$ per day for 5 days, c $=100 \mathrm{ppbv})$. The interday calibration curves $(n=5$ day) are summarized in Table S1 and Figure S6. There is no significant difference for the interday calibration curves in 5 days, indicating the excellent stability of the developed device for monitoring interday $\mathrm{NO} 2$.

The potential interferent effects have been tested by spiking a certain amount of $\mathrm{NO}, \mathrm{SO}_{2}, \mathrm{H}_{2} \mathrm{~S}, \mathrm{NH}_{3}$, and $\mathrm{CO}_{2}$ in the detection of $\mathrm{NO}_{2}$ by using the device. The experimental results confirm that for $100 \mathrm{ppbv}$ of $\mathrm{NO}_{2}$ and within a $\pm 5 \%$ error range, $2000 \mathrm{ppbv}$ of $\mathrm{NO}, \mathrm{SO}_{2}, \mathrm{H}_{2} \mathrm{~S}$, and $\mathrm{NH}_{3}$, and 500000 ppbv of $\mathrm{CO}_{2}$ do not interfere with the detection of $\mathrm{NO}_{2}$. In addition, because the GS reagent solution is kept in the PPMT with the nominal pore size of $0.2 \mu \mathrm{m}$, the dominant interferent effects from atmospheric particulate matters are coincidentally avoided. The selectivity of the developed device should be better than the standard method (HJ 479-2009) and appropriate for the detection of $\mathrm{NO}_{2}$ in urban air.

Validation and Application of the Device for Urban Air Analysis. The performance of the assembled device has been evaluated by monitoring $\mathrm{NO}_{2}$ in urban air samples. Air samples collected in air bags from Songling Road and the QIBEBT campus have been analyzed by the assembled device and the standard method (HJ 479-2009), respectively (Table 1). For the standard method, due to the different coexisting

Table 1. Analytical Results of $\mathrm{NO}_{2}$ Concentrations Determined in Urban Air by the Assembled Device and the Standard Method (HJ 479-2009)

\begin{tabular}{cccc} 
date & sampling location & $\begin{array}{c}\text { present method/ } \\
\text { ppbv }\end{array}$ & $\begin{array}{c}\text { standard method/ } \\
\text { ppbv }\end{array}$ \\
\hline Jan. 21 & QIBEBT campus & $50.0 \pm 13.7$ & $53.3 \pm 25.0$ \\
Jan. 22 & QIBEBT campus & $111.8 \pm 12.4$ & $114.8 \pm 14.1$ \\
Feb. 23 & Songling road side & $144.6 \pm 4.7$ & $151.3 \pm 7.9$ \\
Mar. 01 & Songling road side & $223.5 \pm 7.2$ & $225.6 \pm 7.5$ \\
\hline
\end{tabular}

species with various concentration levels in each sample, the interferent effects are varied in each detection, leading to the diverse deviations of the detection results. Through application of the similar colorimetric mechanism, the similar trend of the deviations between the present method and the standard method (HJ 479-2009) is expected. The results obtained by our device are highly consistent with those of the standard method, indicating its candidate role of the standard method. Additionally, its application potential has also been evaluated by continuously monitoring atmospheric $\mathrm{NO}_{2}$. The results from air samples collected at the same locations in 10 different days (March 16 25, 2017) and in certain periods of one day are shown in Figure 3. $\mathrm{NO}_{2}$ levels in the QIBEBT campus are all slightly lower than that of the Songling Road roadside (Figure $3 \mathrm{a}, \mathrm{b})$, corresponding to its distance from Songling Road (i.e., > $50 \mathrm{~m}$ ). For the air samples in certain periods of 1 day, the variations of atmospheric $\mathrm{NO}_{2}$ can be distinguished and recorded at every $4 \mathrm{~min}$ (Figure 3c). For example, the $\mathrm{NO}_{2}$ concentrations in the QIBEBT campus were at a low level (0$50 \mathrm{ppbv}$ ) from 2:55 to 3:24 p.m., while it increased to $100 \mathrm{ppbv}$ rapidly after 3:24 p.m. and then kept at a high level (ca. 100200 ppbv) until about 5:26. The results were in agreement well with the vehicular traffic activities on Songling Road, where heavy traffic starts at around 3:30 p.m. The vehicle exhaust gas was further confirmed as a main source of $\mathrm{NO}_{2}$ in urban air.

\section{CONCLUSION}

By employing a light-emitting diode as the light source, a photodiode as the detector, and the Griess-Saltzman reaction as the quantitation basis, a high time-resolution optical sensor for monitoring atmospheric $\mathrm{NO}_{2}$ has been developed. The device presents a set of excellent properties, such as good intraday and interday precision, a low RSD and LOD, and high time resolution. When used for monitoring $\mathrm{NO}_{2}$ in the urban 


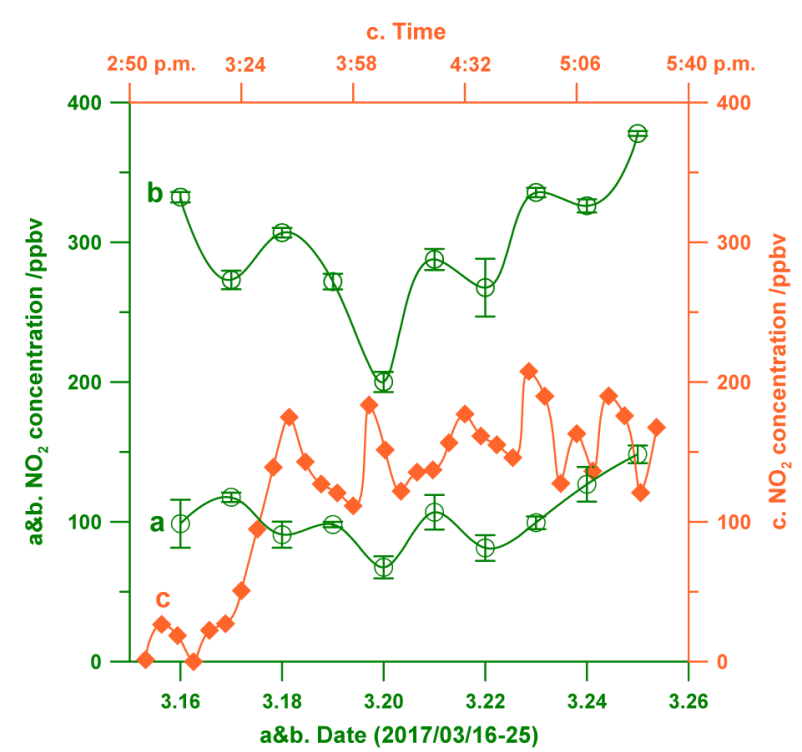

Figure 3. $(\mathrm{a}, \mathrm{b})$ Results of $\mathrm{NO}_{2}$ concentration detected in the air of the QIBEBT campus (a) and Songling Road side (b) from March 16 to 25. (c) The $\mathrm{NO}_{2}$ concentration monitored by the device from 2:55 to 5:30 p.m. on the QIBEBT campus (time solution $15 \mathrm{~h}^{-1}$ ).

air, the variations in periods of 10 days (one sample per day) and about $3 \mathrm{~h}$ (one sample per $4 \mathrm{~min}$ ) can be precisely recorded. The results suggested that the developed device has great potential in routine $\mathrm{NO}_{2}$ analysis in both the laboratory and the field.

\section{ASSOCIATED CONTENT}

\section{S Supporting Information}

The Supporting Information is available free of charge on the ACS Publications website at DOI: 10.1021/acs.analchem.7b03578.

Reagents and samples, experimental procedures for standard $\mathrm{NO}_{2}$ detection, experimental procedures for urban air analysis, data analysis, additional figures, and tables (PDF)

\section{AUTHOR INFORMATION}

\section{Corresponding Authors}

*Fax/Tel: +86 532-80662709; E-mail: zhaozs@qibebt.ac.cn (Z.Z.)

*Fax: +86 24 83676698; Tel: +86 24 83688944; E-mail: chenxuwei@mail.neu.edu.cn (X.-W.C.)

\section{ORCID}

Yong Tian: 0000-0001-9936-3781

Ming-Li Chen: 0000-0001-8536-8864

Xu-Wei Chen: 0000-0001-7189-5022

\section{Notes}

The authors declare no competing financial interest.

\section{ACKNOWLEDGMENTS}

The present study was supported by the National Natural Science Foundation of China (No. 21607161), the Scientific Instrument Developing Project of the Chinese Academy of Sciences (No. YZ201642), the Livehood Science and Technology Program of Qingdao City (No. 15-9-2-123 ns), the Primary Research \& Developement Plan of Shandong Province (No. 2016GSF117039) and the State Key Laboratory of Environmental Chemistry and Ecotoxicology, Research Center for Eco-Environmental Sciences, Chinese Academy of Sciences (No. KF2015-10). Y.T. thanks Dr. Dasgupta P.K. (The University of Texas at Arlington) for his idea and suggestion in HCN detection that was performed in this study.

\section{REFERENCES}

(1) Brewer, A. W.; McElroy, C. T.; Kerr, J. B. Nature 1973, 246, 129-133.

(2) United States Environmental Protection Agency (EPA). National Ambient Air Quality Standards Table. www.epa.gov/criteria-airpollutants/naaqs-table.

(3) Richter, A.; Burrows, J. P.; Nuss, H.; Granier, C.; Niemeier, U. Nature 2005, 437, 129-132.

(4) Green, L. Science 1967, 156, 1448

(5) Yuan, W.; Huang, L.; Zhou, Q.; Shi, G. ACS Appl. Mater. Interfaces 2014, 6, 17003-17008.

(6) Brunekreef, B.; Holgate, S. T. Lancet 2002, 360, 1233-1242.

(7) Chauhan, A. J.; Inskip, H. M.; Linaker, C. H.; Smith, S.; Schreiber, J.; Johnston, S. L.; Holgate, S. T. Lancet 2003, 361, 19391944.

(8) Chauhan, A. J.; Krishna, M. T.; Frew, A. J.; Holgate, S. T. Rev. Environ. Health 1998, 13, 73-90.

(9) Bauer, U.; Berg, D.; Kohn, M. A.; Meriwether, R. A.; Nickle, R. A. Public Health Rep. 1998, 113, 62-70.

(10) Ambient air quality standards, GB 3095-2012; Ministry of Environmental Protection of the People's Republic of China: Beijing, China, 2012; http://kjs.mep.gov.cn/hjbhbz/bzwb/dqhjbh/dqhjzlbz/ 201203/t20120302 20224165.shtml.

(11) European Commission. Air Quality Standards. http://ec.europa. eu/environment/air/quality/standards.htm.

(12) Jarvis, D. J.; Adamkiewicz, G.; Heroux, M.-E.; Rapp, R.; Kelly, F. J. Nitrogen dioxide. In WHO Guidelines for Indoor Air Quality: Selected Pollutants; World Health Organization: Geneva, Switzerland, 2010. https://www.ncbi.nlm.nih.gov/books/NBK138707/.

(13) Qi, B.; Wang, Z. Q.; Yang, H. Y.; Liu, B. Y.; Ma, Y.; Yang, B. Chin. J. Anal. Chem. 2010, 38, 607-610.

(14) Mikuska, P.; Vecera, Z. Anal. Chim. Acta 2000, 410, 159-165.

(15) Yan, Y.; Krishnakumar, S.; Yu, H.; Ramishetti, S.; Deng, L.-W.; Wang, S.; Huang, L.; Huang, D. J. Am. Chem. Soc. 2013, 135, 53125315.

(16) Neuberger, D.; Duncan, A. B. F. J. Chem. Phys. 1954, 22, $1693-$ 1696.

(17) Yan, Y.; Sun, J.; Zhang, K.; Zhu, H.; Yu, H.; Sun, M.; Huang, D.; Wang, S. Anal. Chem. 2015, 87, 2087-2093.

(18) Fine, G. F.; Cavanagh, L. M.; Afonja, A.; Binions, R. Sensors 2010, 10, 5469-5502.

(19) Lin, C.; Gillespie, J.; Schuder, M. D.; Duberstein, W.; Beverland, I. J.; Heal, M. R. Atmos. Environ. 2015, 100, 111-116.

(20) Li, T. L.; Wu, Y. H.; Huang, J. Y.; Zhang, S. Q. Sens. Actuators, B 2017, 243, 566-578.

(21) Hossain, M.; Saffell, J.; Baron, R. ACS Sens. 2016, 1, 1291-1294.

(22) Huang, H. L.; Dasgupta, P. K. Electroanalysis 1997, 9, 585-591.

(23) Salem, A. A.; Soliman, A. A.; El-Haty, I. A. Air Qual., Atmos. Health 2009, 2, 133-145.

(24) Grubner, O.; Goldin, A. S. Anal. Chem. 1973, 45, 944-947.

(25) Wang, Y.; Allen, A.; Mark, D.; Harrison, R. M. J. Environ. Monit. 1999, 1, 423-426.

(26) Leigh, R. J.; Corlett, G. K.; Friess, U.; Monks, P. S. Appl. Opt. 2006, 45, 7504-7518.

(27) Cheng, A. Y. S.; Chan, M. H. Appl. Spectrosc. 2004, 58, 14621468.

(28) Xu, H.; Zhu, H.; Sun, M.; Yu, H.; Li, H.; Ma, F.; Wang, S. Analyst 2015, 140, 1678-1685.

(29) Li, H. H.; Yu, H.; Sun, M. T.; Alamry, K. A.; Asiri, A. M.; Wang, S. H. Int. J. Environ. Sci. Technol. [Online] 2017.10.1007/s13762-0171483-z 
(30) Yan, Y.; Zhang, K.; Yu, H.; Zhu, H.; Sun, M.; Hayat, T.; Alsaedi, A.; Wang, S. Talanta 2017, 174, 387-393.

(31) Yu, H.; Du, L.; Guan, L.; Zhang, K.; Li, Y.; Zhu, H.; Sun, M.; Wang, S. Sens. Actuators, B 2017, 247, 823-829.

(32) Juarez, L. A.; Costero, A. M.; Sancenon, F.; Martinez-Manez, R.; Parra, M.; Gavina, P. Chem. - Eur. J. 2015, 21, 8720-8722.

(33) Ambient air-Determination of nitrogen oxides- $N$-(1-naphthyl) ethylene diamine dihydrochloride spectrophotometric method; HJ. 4792009; Ministry of Environmental Protection of the People's Republic of China: Beijing, China, 2009.

(34) Ohira, S.-I.; Dasgupta, P. K.; Schug, K. A. Anal. Chem. 2009, 81, 4183-4191.

(35) Ratcliff, E. L.; Veneman, P. A.; Simmonds, A.; Zacher, B.; Huebner, D.; Saavedra, S. S.; Armstrong, N. R. Anal. Chem. 2010, 82, 2734-2742.

(36) da Silveira Petruci, J. F.; Cardoso, A. A. Anal. Chem. 2016, 88, 11714-11719.

(37) Ma, J.; Ohira, S.-I.; Mishra, S. K.; Puanngam, M.; Dasgupta, P. K.; Mahon, S. B.; Brenner, M.; Blackledge, W.; Boss, G. R. Anal. Chem. 2011, 83, 4319-4324.

(38) Ohira, S. I.; Wanigasekara, E.; Rudkevich, D. M.; Dasgupta, P. K. Talanta 2009, 77, 1814-1820.

(39) Toda, K.; Yoshioka, K. I.; Ohira, S. I.; Li, J. Z.; Dasgupta, P. K. Anal. Chem. 2003, 75, 4050-4056.

(40) Tian, Y.; Dasgupta, P. K.; Mahon, S. B.; Ma, J.; Brenner, M.; Wang, J.-H.; Boss, G. R. Anal. Chim. Acta 2013, 768, 129-135. 